\title{
Effect of synthetic carbon substrates and cane molasses, an agro waste, on exopolysaccharide production by $\boldsymbol{P}$. fluorescens
}

\author{
A. Sirajunnisa \\ Department of Chemical \\ Engineering, \\ Annamalai University, \\ Annamalainagar 608002, \\ Tamilnadu, India
}

\author{
V.Vijayagopal \\ Department of Chemical \\ Engineering, \\ Annamalai University, \\ Annamalainagar 608002, \\ Tamilnadu, India
}

\author{
T.Viruthagiri \\ Department of Chemical \\ Engineering, \\ Annamalai University, \\ Annamalainagar 608002 \\ Tamilnadu, India
}

\begin{abstract}
Exopolysaccharides (EPS) from P.fluorescens was produced using sucrose and sugarcane molasses as the carbon substrates at different concentrations (1-7\%), at different incubation time (12, 24, 36, 48, 60 and $72 \mathrm{hr})$. The extraction was carried out using ethanol precipitation technique. The lyophilized samples were analysed for its total carbohydrates content. The predominant sugar was found to be glucose by TLC. The functional groups were identified using FT-IR spectroscopy. Maximum production was given by the medium containing $5 \%$ sugarcane molasses and was found to be $2843 \mathrm{mg} / \mathrm{lat} 48 \mathrm{hr}$ after which the production decreased. The EPS production using sugarcane molasses gave comparatively a higher yield than sucrose, which could be commercialized for a cost effective production of this viscous to plastic polymers.
\end{abstract}

Keywords: Pseudomonas fluorescens, sugarcane molasses, exopolysaccharides, FT-IR spectroscopy, biosurfactants.

\section{INTRODUCTION}

Microbes release polysaccharides extracellularly as exopolysaccharides (EPS) in the environment, in the form of capsules or slime. Naturally occurring polysaccharides possess a unique combination of functional properties and environmentally friendly features. They are renewable in nature, non-toxic and biodegradable [1]. Microbial polysaccharides are water soluble polymers and may be ionic or non ionic. EPS are highly important to any bacterium as a defense mechanism, prevent from dessication [2] and for adhesions by forming biofilms, [3, 4] in industries as gelling agents, biosurfactants, emulsifiers, viscosifiers, [5-7] biosorbents [8, 9] and biologically active as antimicrobials, anticancer agents, www.ijsea.com antioxidants [10-13]. Certain commercially available and important microbial EPSs are dextrans, xanthan, gellan, pullulan, yeast glucans and bacterial alginates [14].

Pseudomonads are one of the richest sources of exopolysaccharides. Extracellular slime is a characteristic of certain Pseudomonas strains and the formation of complex exocellular slime has been reported in strains of $P$. aeruginosa under various cultural conditions [15]. Pseudomonas sp. produce bacterial alginates and also gellan type acidic heteropolysaccharides in a laboratory scale [16]. Pseudomonas fluorescens is a common Gram negative, rod shaped bacterium [17]. Pseudomonas fluorescens was found to produce EPS [18]. Marginalan, first produced by P.marginalan HT041B, has also been produced by Pseudomonas fluorescens. EPS from 
Pseudomonas fluorescens play a wider role in heavy metal adsorption [19].EPS is often produced at a lower temperature required for growth than optimum [20]. It also requires higher carbon content in the medium and decreased nitrogen quantity [21]. Factors that could influence the production of EPS are composition of the medium, especially carbon and nitrogen sources and the parameters like $\mathrm{pH}$, temperature and incubation time.

Recent investigations are carried out to produce exopolysaccharides for biotechnological applications at a lower cost. For a cost effective production, agro industrial wastes are used as substrates [22]. Molasses is the final effluent obtained in the production of sugar by repeated crystallization [23]. Sugarcane molasses could be a better source of carbon due to higher content of total sugars $48.3 \%$. The present investigation is the study of effects of synthetic and natural carbon substrate of the production of EPS from bacterial isolate from soil, Pseudomonas fluorescens.

\section{METHODOLOGY}

\subsection{Culture Isolation}

Culture of P.fluorescens was isolated from soil using serial dilution technique on nutrient agar plates. The culture was biochemically characterised and purified on Pseudomonas agar (for Fluorescein) medium (HiMedia Laboratories, Mumbai, India). The culture was periodically subcultured in nutrient broth and stored in the nutrient agar slants at $4{ }^{\circ} \mathrm{C}$ for further studies.

\subsection{Experimental Design -Effect of}

\section{Carbon sources}

Each set consisted nutrient broth with varying concentrations $(1,2,3,4,5,6,7 \%)$ of sugars (Glucose, Fructose, Sucrose, ' ( $2 \%$ inoculum) was added to the five different flasks containing medium with respective sugars and kept in the shaker incubator for 3 days at $37^{\circ} \mathrm{C}$. The culture was checked for EPS production, every $12 \mathrm{hr}$.

www.ijsea.com

\subsection{Use of cane molasses as the carbon substrate}

Sugarcane molasses was obtained from a sugar factory and being used as the raw carbon substrate. Molasses had to be clarified for it to be used in the study [24]. It was diluted with distilled water in the ratio 1:1 with distilled water containing sodium di hydrogen orthophosphate $(2 \mathrm{~g} / \mathrm{l})$. The solution was autoclaved at $121^{\circ} \mathrm{C}$ for $30 \mathrm{~min}$ and left to settle for $24 \mathrm{hr}$. The clarified molasses were then diluted with distilled water at different concentrations $(1,2,3,4,5$, $6,7 \%$ ) and used as raw carbon source for the production of EPS.

\subsection{Isolation, extraction and purification of EPS}

An aliquot of $10 \mathrm{ml}$ of the culture was taken and centrifuged at $11000 \mathrm{rpm}$ for $10 \mathrm{~min}$ at $4^{0} \mathrm{C}$. The supernatant was filtered using a $0.45 \mu \mathrm{m}$ membrane filter. Two volumes of ice cold ethanol was added to the supernatant and left overnight at $4^{0} \mathrm{C}$, after which it was centrifuged at $2500 \mathrm{rpm}$ for $20 \mathrm{~min}$. The pellet collected, was resuspended in demineralised water. The solution was then mixed again with two volumes of ice cold ethanol and centrifuged at 2500rpm for $20 \mathrm{~min}$ at $4^{0} \mathrm{C}$ [25]. The extracted, pelleted EPS was lyophilized and stored for subsequent analyses.

\subsection{Determination of Total Carbohydrate content in EPS}

The total carbohydrate content of extracted EPS was determined by the phenol- sulfuric method, with glucose as the standard [26]. In short, to the EPS sample of $0.1 \mathrm{ml}, 1 \mathrm{ml}$ of $5 \%$ phenol solution was added, after which, $5 \mathrm{ml}$ of concentrated sulfuric acid (96\%) was added. The mixture was mixed gently for $15 \mathrm{~min}$. The sample tubes were kept in water bath for $20 \mathrm{~min}$ at $30^{\circ} \mathrm{C}$. The absorbance was read spectrophotometrically at $490 \mathrm{~nm}$. 


\subsection{Solubility of EPS}

The solubility of EPS was checked using distilled water and various organic solvents. 50mg of the lyophilized EPS of the culture was mixed well, by vortexing, with $1 \mathrm{ml}$ of solvents - water, chloroform, ethanol, butanol, petroleum ether and acetone.

\subsection{Thin Layer Chromatography (TLC)}

TLC plates were prepared with silica gel G (Merck \& Co., Mumbai, India). Plates were developed in ethyl acetate: isopropanol: distilled water $(65: 23.5: 11.5)$. The sugars could be visualized by spraying p-anisaldehyde reagent $(60 \mathrm{ml}$ glacial acetic acid, $0.5 \mathrm{ml}$ concentrated sulfuric acid, $0.5 \mathrm{ml} \mathrm{p}$-anisaldehyde reagent). After spraying, the plates were kept in the hot air oven at $85^{\circ} \mathrm{C}$ till the colored spots appeared. Standard sugar was also spotted for the identification.

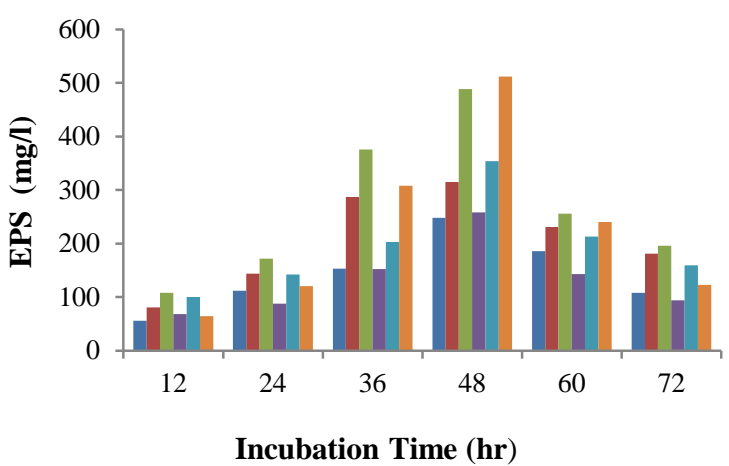

(A)

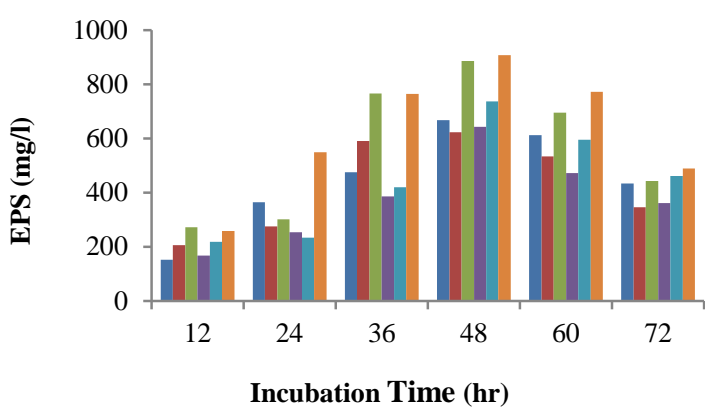

(C)

\subsection{Fourier Transform Infrared Spectroscopy (FT-IR)}

EPS was characterized using FT-IR spectrophotometer (ParkinElmer, Thane, India). The dried EPS sample $(0.5 \mathrm{mg})$ was ground with $250 \mathrm{mg}$ of $\mathrm{KBr}$ and pelleted using hydraulic press for FT-IR Spectroscopy, between frequency, $4000-450 \mathrm{~cm}^{-1}$.

\section{RESULTS AND DISCUSSION}

The below indicated figures (Figure 1) show the productivity of EPS by the strain in the presence of different synthetic carbon substrates viz., glucose, fructose, sucrose, lactose, rhamnose and the agro waste, cane molasses, used as the natural carbon substrate, at varying incubation time $-12,24,36,48,60,72$ at different concentrations $-1-7 \%$, with an interval of $1 \%$.

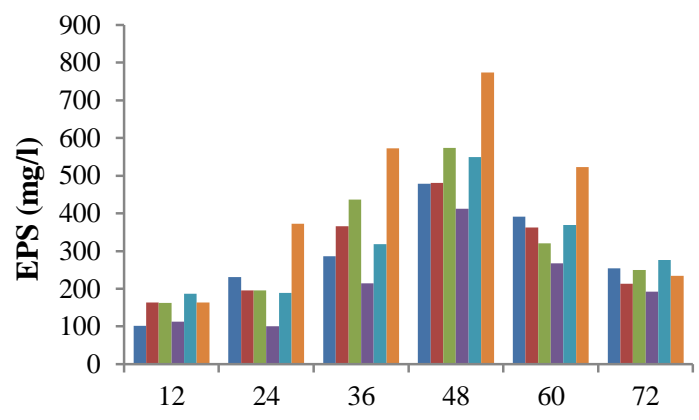

Incubation Time (hr)

(B)

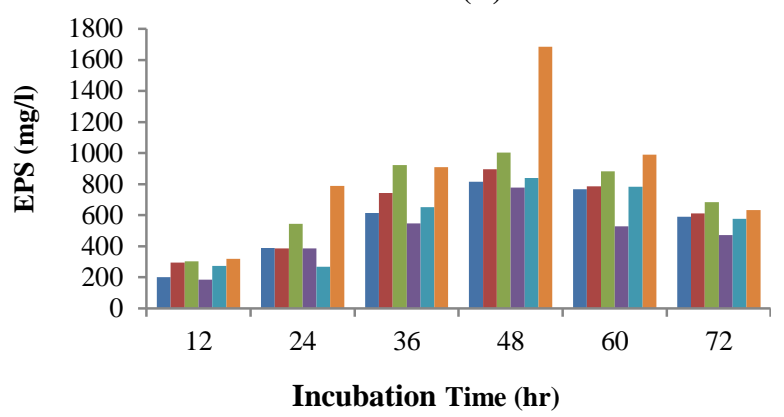

(D) 


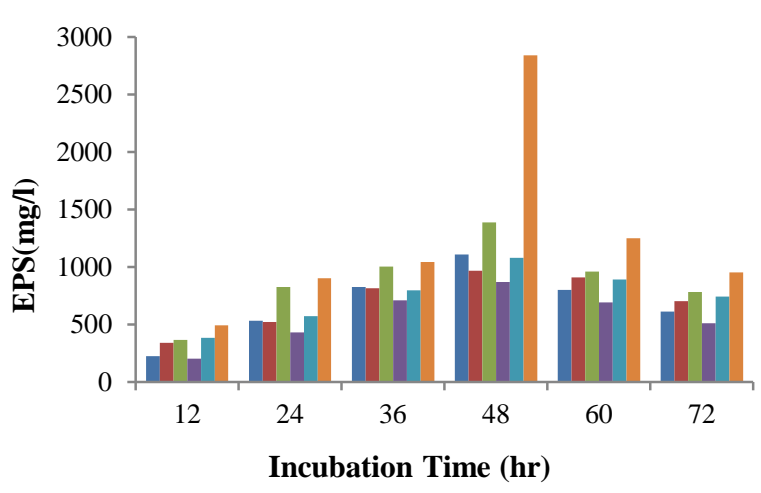

(E)

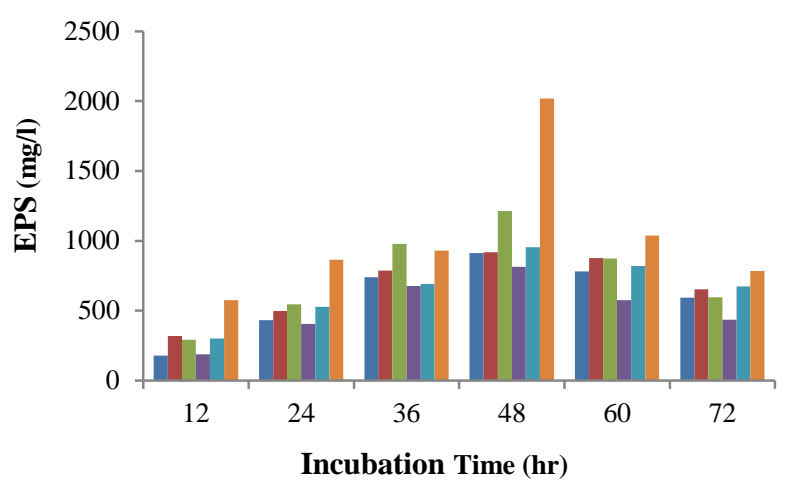

(F)

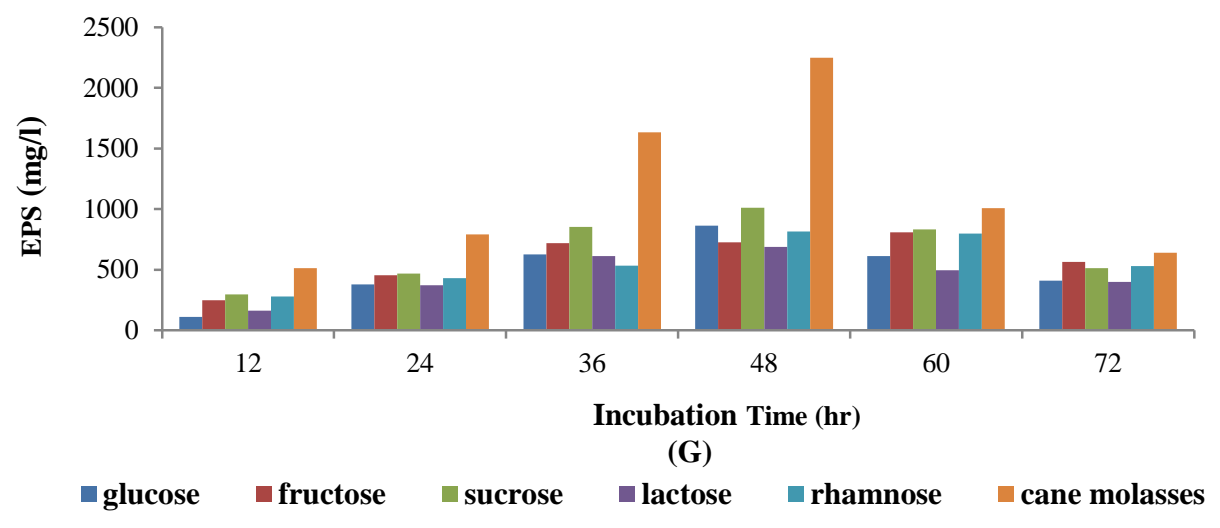

Figure 1 Represents yield of EPS (mg/l) using synthetic and agro substrates at varying time periods $(12,24,36,48,60,72$ hr) at different concentrations - 1\%-(A), 2\%-(B), 3\%-(C), 4\%-(D), 5\%-(E), $6 \%$-(F) \& 7\%-(G)

min. It was observed that the yield of EPS was more with

The batch study showed that the maximum EPS production the $5 \%$ cane molasses $(2843 \mathrm{mg} / \mathrm{l})$, than that with the occurred at $48^{\text {th }} \mathrm{hr}$ after which the yield gradually synthetic substrate, sucrose, producing 1389mg/l (Figure decreased. This is apparently due to the decline in the growth of the culture, which has the doubling time of 120

2). The study revealed that the higher the concentration of sucrose, the lower was the production of EPS.

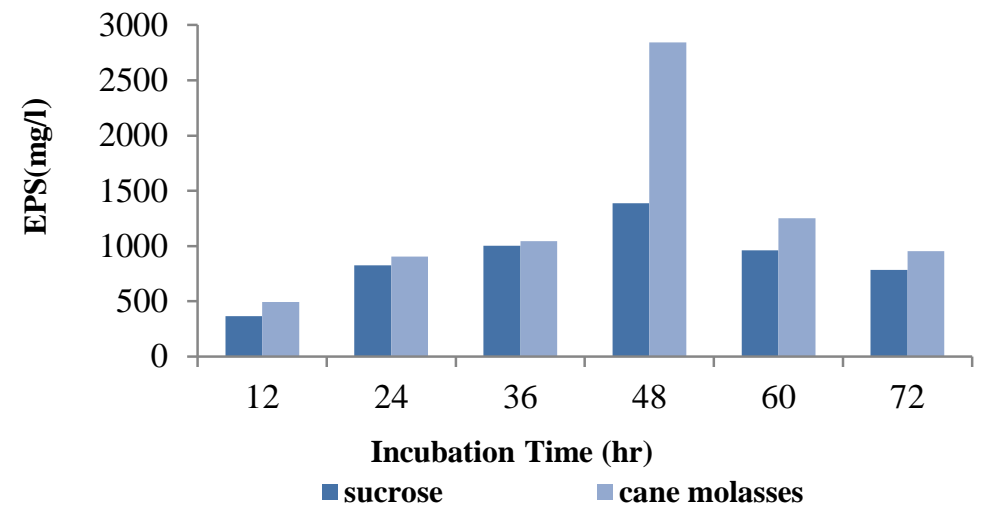

Figure 2 Represents the production of EPS at $5 \%$ concentration of sucrose and case molasses 
Similar reports show higher production of exopolymers using cheaper substrates. P.aeruginosa produced higher EPS in presence of beet molasses and possessed antimicrobial activity. Molasses is effective in growth medium, since it includes vitamins and minerals and has a significant growth stimulatory effect [11]. Use of date syrup as the substrate by X.campestris reported a higher yield of $0.89 \mathrm{~g} / 100 \mathrm{ml}$ after $96 \mathrm{hr}$, than that produced in sucrose medium $(0.18 \mathrm{~g} / 100 \mathrm{ml})$ [27].EPS was found to be completely soluble in distilled water and insoluble in chloroform, petroleum ether, ethanol, butanol and acetone. This indicates the presence of hydroxyl groups binding with water molecules, thus revealing the polar nature of the isolated exopolymer. Due to the presence of many number of hydroxyl groups, strong attractive forces prevail between polysaccharides, which make them insoluble in organic solvents [28].

Total carbohydrate analysis showed that the polysaccharide was composed of $73.9 \%$ sugar. The FTIR spectroscopy analysis of the $P$. fluorescens EPS showed the presence of the vibrational stretching of $\mathrm{OH}$ groups at $3430.23 / \mathrm{cm}$. Vibrational spectrum could be observed for CO-CC group between 1490.47-1062.93/cm [29-31]. These results indicate the presence of glucose units in the polysaccharide. Thin Layer Chromatography (TLC) analysis of the EPS samples revealed the presence of Glucose, when referred to the $R_{f}$ value of respective standard sugar (0.18). Reports show that EPS from $P$. fluorescens has other sugars like rhamnose, galactose, allose, inositol along with uronic acids and phosphates [32].

\section{CONCLUSION}

Production of cheap, microbial EPS from different sources is the recent interest of the polymer based researchers. Many investigations had been carried out to generate these biodegradable, harmless and nontoxic polysaccharides. The present study showed the production of exopolysaccharides by $P$. fluorescens using a cheaper carbon substrate, cane molasses. It had yielded a higher amount of EPS (2843mg/l), than when grown with sucrose. The physical www.ijsea.com characterization had showed that the predominant sugar present in the EPS is the monosaccharide, Glucose. Further researches can be focused elucidating the structure of the extracted EPS.

\section{REFERENCES}

[1] Filomena, F., Alves, V.D., and Maria Reis, A.M. 2011. Advances in bacterial Exopolysaccharides: from production to biotechnological applications. Trends in Biotechnology, 29 (8), 388-398.

[2] Bhaskar, P.V., and Bhosle, N.B. 2006. Baterial extracellular polymeric substance carrier of heavy metals in the marine food-chain. Environ Int. 32 (2), 191-198.

[3] Hinsa, S.M., and O'Toole, G.A. 2006. Biofilm formation by Pseudomonas fluorescens WCS365: a role for LapD. Microbiology. 152, 1375-1383.

[4] Pamp, S.J., Gjermansen, M., and Tolker-Nielsen, T. The biofilm Matrix: A Stricky Framework.

[5] Bryan, B.A., Linhardt, R. J., and Daniels, L. 1986. Variation in composition and yield of exopolysaccharides produced by Klebsiella $s p$. strain K32 and Acenitobacter calcoaceticus BD4. Appl. Environ. Microbiol. 51(6), 1304-1308.

[6] Surekha, K., Satpute, Ibrahim, Banat, M., Prashant, K., Dhakephalkar, Banpurkar, A.G., Balu, Chopade, A. 2010. Biosurfactants, bioemulsifiers and exopolysaccharides from marine microorganisms. Biotechnology Advances. 28, 436-450.

[7] Poli, A., Anzelmo, G., and Nicolaus, B. 2010. Bacterial Exopolysaccharides from Extreme Marine Habitats: Production, Characterization and Biological Activities. Mar. Drugs 8, 1779-1802.

[8] de Oliveira Martins, P.S., de Almeida, N.F., and Ferreira Leite, S.G, 2008. Application of a bacterial extracellular polymeric substance in heavy metal adsorption in a co-contaminated aqueous system. Brazilian Journal of Microbiology. 39, 780-786. 
[9] Moppert, X., Le Costaouec, T., Ragunenes, G., Courtois, A., Simon- Colin, C., Crassous, P., Costa, B., and Guezennec, J. 2009. Investigations into the uptake of copper, iron and selenium by a highly sulphated bacterial exopolyaccharide isolated from microbial mats. Journal of Industrial Microbiology and Biotechnology. 36(4), 599-604.

[10] Kocharin, K., Rachathewe, P., Sanglier, J.J., and Prathumpai, W. 2010. Exobiopolymer production by Ophiocordyceps diterigena BCC 2073: optimization, production in bioreactor and characterization. BMC Biotechnology. 10 (51).

[11] Onbasli, D., and Aslim, A. 2008. Determination of antimicrobial activity and production of some metabolites by Pseudomonas aeruginosa B1 and B2 in sugar beet molasses. African Journal of Biotechnology. 7 (24), 4614-4619.

[12] Liu, J., Luo, J., Ye, H., Sun, Y., Lu, Z., and Zeng, X. 2010. In vitro and in vivo antioxidant activity of exopolysaccharides from endophytic bacterium Paenibacillus polymyxa EJS-3. Carbohydrate Polymers. 82, 1278-1283.

[13] Liu, C.T., Chu, F.J., Chou, C.C., and Yu, R.C. 2011. Antiproliferative and anticytotoxic effects of cell fractions and exopolysaccharides from Lactobacillus casei 01. Mutation Research.

[14] Banik, R. M., Kanari, B., and Upadhyay, S.N. 2000. Exopolysaccharide of the gellan family: Prospects and potential. World Journal of Microbiology. 16, 407-414.

[15] Williams, A.G., and Wimpenny, J.W.T. 1977. Exopolysaccharide Production by Pseudomonas NCIB 1264 Grown in Batch Culture. Journal of General Microbiology, 102, 13-21.

[16] Palleroni, N.J. 1984. Pseudomonadaceae Bergey's Manual of Systematic Bacteriology. Krieg, N. R. and Holt J.G. (editors) Baltimore: The Willliams and Wilkins Co. 141-149.

[17] Osman, S.F., Fett, W.F., Irwin, P., Brouillette, J.N., and Connor, J.V.O. 1997. The structure of the www.ijsea.com exopolysaccharides of Pseudomonas fluorescens strain H13. Carbohydrate Research. 300, 323-327.

[18] Hung, C.C., Santschi, P.H., and Gillow, J.B. 2005. Isolation and characterization of extracellular polysaccharides produced by Pseudomonas fluorescens Biovar II. Carbohydrate Polymers. 61,141-147.

[19] Celik,G.Y., Aslim, B., and Beyatil, Y. 2008. Characherization and production of the exoplysaccharide (EPC) from Pseudomonas aeruginosa GI and Pseudomonas putida G12 strains. Carbohydrate Polymers. 73, 178-182.

[20] Fett, W.F. 1993. Bacterial exopolysaccharides: Their nature, regulation and role in host-pathogen interactions. Current Topics in Botanical Research, $1,367-390$.

[21] De Vuyst, L., and Degeest, B. 1999. Heteropolysaccharides from lactic acid bacteria. FEMS Microbiology Reviews, 23, 153-177.

[22] Muthusamy, K., Gopalakrishnan, S., Kochupappy Ravi, T., and Sivachidambaram, P. 2008. Biosurfactants: Properties, Commercial production and application. Current science. 94 (6).

[23] Olbrich, H. 2006. The Molasses. BiotechnologieKempe GmbH Publishers. pp. 1-131.

[24] Fusconi, R., Lezi Godinno, M.J., and Segnini Bossolan, N.L., 2008. Culture and exopolysaccharides production from sugarcane molasses by Gordonia polyisoprenivorans CCT 7137 , isolated from contaminated groundwater in Brazil. World Journal of Microbiology and Biotechnology. 24, 7, 937-943.

[25] Savadogo, A., Savadogo, C.W., Barro, N., Ouattara, A.S., Traore, A.S. 2004. Identification of exopolysaccharides producing lactic acid bacteria from Burkino Faso fermented milk samples. African Journal of Biotechnology. 3(3). 189-194.

[26] Dubois, M., Giles, K.A., Hamilton, J. K. Rebers, P. A. and Smith, F. 1956. Colorimetric method for determination of sugars and related substances. Anal. Chem. 28, 350-356. 
[27] Moosavi-Nasab, M., Shekaripour, F. and Alipoor, M. 2008 \& 2009. Use of Date Syrup as Agricultural Waste for Xanthan Production by Xanthomonas campestris. Iran Agricultural Research. 27(1-2), and 28(1).

[28] Patil, S.V., Patil, C. D., Salunke, B.K., Salunkhe, R.B., Bathe, G.A., and Patil, D.M. 2011. Studies on Characterization of Bioflocculant Exopolysaccharide of Azotobacter indicus and Its Potential for Wastewater Treatment. Appl Biochem Biotechnol., 163:463-472.

[29] Rui, L., Wei-Chang, C., Peng, W., Yan, T.W., Guang, Z.G., 2009. Extraction, characterization of Astragalus polysaccharides and its immune modulating activities in rats with gastric cancer. Carbohydrate Polymers. 78,738- 742.

[30] Ibrahim, M., Alaam, M., EI-Haes, H., Jalbout, A.F., de Leon, A. 2006. Analysis of the structure and vibrational spectra of glucose and fructose, Ecl. Quim., Sao Paulo, 31(3): 15-21.

[31] Parikh, A., and Madamwar, D. 2006. Partial characterization of extracellular polysaccharides from Cyanobacteria. Bioresource Technology 97, 1822-1827.

[32] Hung, C.C., Santschi, P.H., and Gillow, J.B. 2005. Isolation and characterization of extracellular polysaccharides produced by Pseudomonas fluorescens Biovar II. Carbohydrate Polymers, 61, 141-147. 